\title{
Chikungunya Viral Infection Requiring Intensive Care - Experience in a Tertiary Care Hospital in Bangladesh
}

\author{
Nazneen $\mathrm{S}^{\mathrm{a}^{*}}$, Saha $\mathrm{M}^{\mathrm{b}^{*}}$, Hossain $\mathrm{R}^{\mathrm{c}}$, Ahsan ASMA ${ }^{\mathrm{d}}$, Fatema $\mathrm{K}^{\mathrm{e}}$, Ahmed $\mathrm{F}^{\mathrm{f}}$, Saha DK ${ }^{\mathrm{g}}$, Sultana $\mathrm{R}^{\mathrm{h}}$
}

\begin{abstract}
Background: Chikungunya fever is a benign self-limiting viral illness. Although it is considered as a nonfatal disease but in elderly patients who have co-morbidities can present with atypical life threatening clinical menifestations which may cause significant morbidity and mortality. The Aim of this study is to observe atypical presentations, various complications and outcome of chikungunya fever.
\end{abstract}

Methods: This was a cross sectional observational study was carried out on 23 adult patients with chikungunya fever from $1^{\text {st }}$ June to $31^{\text {st }}$ July of 2017 in the Department of Critical Care Medicine of BIRDEM General Hospital, Dhaka, Bangladesh.

Results: Total 23 patients were included in this study, male 83\% and female 17\%.From indoor 17(73.9\%) patients got admitted in ICU, 3(13\%) patients came directly from home and 3(13\%) patients from another hospitals. Most of the patients were elderly having co-morbidities like diabetes, Hypertension, IHD and CKD. COPD and CVD were also present in a few numbers of patients. Most of the patients had fever, arthralgia and headache but respiratory distress (73.9\%), altered mental status (56.5\%), vomiting (21.7\%), diarrhoea (17.3\%) and low urine output (17.3\%) are the causes of ICU admission. Major Organ involvement of the study subjects were respiratory system (52.1\%), renal system (47.8\%), CVS (34.7\%) and nervous system (34.7\%). Among 23, $16(70 \%)$ patients improved and $4(17 \%)$ patients died in ICU.

Conclusion: This study highlights that though chikungunya fever is considered as a benign non-fatal disease it can produce life threatening clinical menifestations and serious complications requiring Intensive Care particularly in elderly comorbid patients and can cause high mortality.

Key words: Chikungunya fever, Intensive Care Unit.

(BIRDEM Med J 2018; 8(1): 16-20)

Author Information

a. Dr. Suraiya Nazneen, Registrar, Department of Critical Care Medicine, BIRDEM General Hospital, Dhaka

b. Dr. Madhurima Saha, Registrar, Department of Critical Care Medicine, BIRDEM General Hospital, Dhaka

c. Dr. Rakib Hossain, Resident Medical Officer, Department of Critical Care Medicine, BIRDEM General Hospital, Dhaka

d. Prof. ASM Areef Ahsan, Professor and Head, Department of Critical Care Medicine, BIRDEM General Hospital, Dhaka

e. Dr. Kaniz Fatema, Associate Professor, Department of Critical Care Medicine, BIRDEM General Hospital, Dhaka

f. Dr. Fatema Ahmed, Associate Professor, Department of Critical Care Medicine, BIRDEM General Hospital, Dhaka

g. Dr. Debasish Kumar Saha, Registrar, Department of Critical Care Medicine, BIRDEM General Hospital, Dhaka

h. Dr. Rozina Sultana, Critical Care Specialist, Department of Critical Care Medicine, BIRDEM General Hospital, Dhaka

*First two authors had equal contributions and should be regarded as Principal author

Corresponding author: Dr. Suraiya Nazneen, Registrar, Department of Critical Care Medicine. BIRDEM General Hospital, Shahbag, Dhaka. Email: drnazneen28@gmail.com

Received: August 19, 2017

Accepted: October 31, 2017

\section{Introduction}

Chikungunya virus (CHIKV) is a mosquito-transmitted alphavirus that belongs to the Togaviridae family. ${ }^{1}$ It causes chikungunya fever (CHIK fever), a febrile illness associated with severe arthralgia and rash. ${ }^{2-5}$ Aedes aegypti, Aedes albopictus commonly involved in the transmission, although Culex has also been reported for the transmission in some cases. ${ }^{1,6,7}$ Usual symptoms of CHIKV infection include high fever, rigor, headache, photophobia and a petechial or maculapapular rash. In addition, most infected individuals complain of severe joint pain that is often incapacitating and a painful inguinal lymphadenopathy was also reported in some cases. ${ }^{8}$ The illness is usually self-limiting and resolves with time. Supportive care with rest is indicated during the acute joint symptoms. ${ }^{8,9}$ Infective persons should be protected from further mosquito exposure so that they cannot contribute to the transmission cycle. ${ }^{10}$ For diagnosis, monitoring, detection and genotyping of 
CHIKV, conventional reverse transcription-polymerase chain reaction (RT-PCR) methods have been used in the 1st week of illness. Anti-CHIKV antibodies can be detected in patients shortly after symptom onset, usually after 5 days for IgM and a few days later for $\operatorname{IgG}^{8,11}$ The virus was first reported in 1952 in Tanzania.The virus is geographically distributed in Africa, Southeast Asia and India. Sporadic cases are regularly reported from different countries in the affected regions. ${ }^{12}$ During December 2008, an investigation team from the Institute of Epidemiology, Disease Control and Research (IEDCR) and International Centre for Diarrhoeal Disease Research, Bangladesh (ICDDR,B) investigated and detected the first outbreak of chikungunya fever in the Rajshahi and Chapianawabganj districts of Bangladesh. ${ }^{13}$

Though it is thought to be a benign non-fatal self-limiting viral illness atypical presentations of CHIKV infection can involve almost every organ system. Several life threatening extra-articular manifestations reported in the literature involve the nervous system ${ }^{14-16}$ and the eye ${ }^{17}$; alterations in the gastrointestinal tract, liver, kidney, muscles, mucous membranes and skin and hematologic cells have been evidenced as well as in hemostasis and coagulation processes. Cardiovascular compromise is worthy of mentioning because of its usually fatal outcomes. Infection can lead to cardiovascular manifestations, but in addition, patients with existing cardiovascular disease can deteriorate quickly, worsening the short-term prognosis; fatal outcomes seen in patients with diabetes, lupus; or neurological, renal, pulmonary and cardiovascular insufficiency. ${ }^{18-20}$ And the aim of this study was to highlight life threatening menifestations, complications and probable outcome of chikungunya fever in intensive care unit (ICU).

\section{Methods}

This cross-sectional study was carried out on 23 adult patients with chikungunya fever from $1^{\text {st }}$ June to $31^{\text {st }}$ July of 2017 in the Department of Critical Care Medicine of BIRDEM General Hospital, Dhaka, Bangladesh, a tertiary care hospital. All patients were confirmed chikungunya cases either by RT-PCR or IgM antibody from serum or cerebrospinal fluid. One patient had chikungunya and dengue co-infection. The data were collected using a semi-structured proforma. Statistical analysis is done by SPSS version 22.0.

\section{Results}

Total 23 patients were included in this study, male $19(83 \%)$ and female (17\%). From indoor 17(73.9\%) patients got admitted in ICU, $3(13 \%)$ patients came directly from home and $3(13 \%)$ patients from another hospitals.

Table I . Age distribution of the patients $(n=23)$

\begin{tabular}{lcc}
\hline Age & Patient & Percentage (\%) \\
\hline $20-30$ & 0 & 0 \\
$31-40$ & 1 & 4.3 \\
$41-50$ & 1 & 4.3 \\
$51-60$ & 4 & 17.3 \\
$61-70$ & 5 & 21.7 \\
$71-80$ & 9 & 39.1 \\
$81-90$ & 3 & 13 \\
\hline
\end{tabular}

Table II. Comorbidities of the study subjects ( $\mathrm{n}=23$ )

\begin{tabular}{lcc}
\hline Comorbidities & Patient & Percentage (\%) \\
\hline DM & 22 & 96 \\
HTN & 14 & 61 \\
IHD & 8 & 35 \\
CKD & 4 & 17 \\
COPD & 3 & 13 \\
CVD & 2 & 9 \\
\hline
\end{tabular}

Table III. Clinical features of study subjects $(\mathrm{n}=23)$

\begin{tabular}{lcc}
\hline Clinical features & Frequency & Percentage \\
\hline Fever & 23 & 100.0 \\
Joint pain & 9 & 39.1 \\
Rash & 5 & 21.7 \\
Headache & 10 & 43.4 \\
Myalgia & 11 & 47.8 \\
Pruritus & 1 & 4.3 \\
Low urine output & 4 & 17.3 \\
Oedema & 2 & 8.7 \\
Altered Mental status & 13 & 56.5 \\
Respiratory distress & 17 & 73.9 \\
Chest pain & 1 & 4.3 \\
Cough & 4 & 17.3 \\
Vomiting & 5 & 21.7 \\
Diarrhea & 4 & 17.3 \\
Bleeding & 0 & 0 \\
Eye congestion & 0 & 0 \\
\hline
\end{tabular}


Table IV. Causes of ICU admission of the study subjects related to chikungunya (Most of the patients had more than one organ involvement during ICU admission). ( $n=23)$

\begin{tabular}{lcc}
\hline Organ involvement & Number of patients & Percentage \\
\hline Nervous System (Meningoencephalitis , GBS) & 8 & $34.7 \%$ \\
Respiratory System(Pneumonia) & 12 & $52.1 \%$ \\
CVS (Myocarditis, Hypotension ) & 8 & $34.7 \%$ \\
Renal System (AKI) & 11 & $47.8 \%$ \\
\hline
\end{tabular}

Table V. Blood count of study subjects

\begin{tabular}{llll}
\hline INV parameters & Level & $\mathrm{n}=23$ & Mean \\
\hline Leucocytes $\left(/ \mathrm{mm}^{3}\right)$ & $<4000$ & $3(13.0 \%)$ & $10033.9 \pm 4315.8$ \\
& $4000-11000$ & $15(65.2 \%)$ & \\
Lymphocyte $(\%)$ & $>11000$ & $5(21.7 \%)$ & $11.6 \pm 8.3$ \\
& $<20 \%$ & $21(91.3 \%)$ & $190260.9 \pm 128688.2$ \\
Platelet $\left(/ \mathrm{mm}^{3}\right)$ & $20-50 \%$ & $2(8.7 \%)$ & \\
& $>50 \%$ & 0 & $10(43.4 \%)$ \\
\end{tabular}

Table VI. Other laboratory parameters of the patients

\begin{tabular}{llll}
\hline INV parameters & Level & $\mathrm{n}=23$ & Mean \\
\hline $\mathrm{Na}(\mathrm{mmol} / \mathrm{l})$ & $<136$ & $16(69.5 \%)$ & $129.8 \pm 8.8$ \\
& $136-148$ & $7(30.4 \%)$ & \\
& $>148$ & 0 & $4.0 \pm 0.8$ \\
$\mathrm{~K}(\mathrm{mmol} / \mathrm{l})$ & $<3.5$ & $7(30.4 \%)$ & \\
& $3.5-5.2$ & $13(56.5 \%)$ & \\
& $>5.2$ & $3(13 \%)$ & $7.5 \pm 0.7$ \\
$\mathrm{Ca}(\mathrm{mg} / \mathrm{dl})$ & $<8.4$ & $22(95.6 \%)$ & \\
& $8.4-10.4$ & $1(4.3 \%)$ & $203.6 \pm 411.5$ \\
Aspertate transaminase $(\mathrm{U} / \mathrm{L})$ & $>10.4$ & 0 & \\
& $<37$ & $8(34.8 \%)$ & $94.0 \pm 132.8$ \\
Alanine transaminase (U/L) & $>37$ & $15(65.2 \%)$ & \\
& $>40$ & $9(39.1 \%)$ & $70.6 \pm 66.4$ \\
Urea(mg/dl) & $>40$ & $14(60.8 \%)$ & \\
S Cr.(mg/dl) & $10-45$ & $13(56.5 \%)$ & $2.7 \pm 2.9$ \\
& $>45$ & $10(43.4 \%)$ & \\
\hline
\end{tabular}


Table VII. CPK and LDH of the patients

\begin{tabular}{llll}
\hline INV parameters & Level & Frequency & Mean \\
\hline CPK (U/L)n=14 & $<210$ & $5(35.7 \%)$ & $3358.3 \pm 7061.7$ \\
& $>210$ & $9(64.2 \%)$ & \\
LDH (U/L)n=10 & $230-460$ & $3(30 \%)$ & $4098.7 \pm 9659.9$ \\
& $>460$ & $7(70 \%)$ & \\
\hline
\end{tabular}

CPK-Creatine phosphokinase LDH- Lactate dehydrogenase

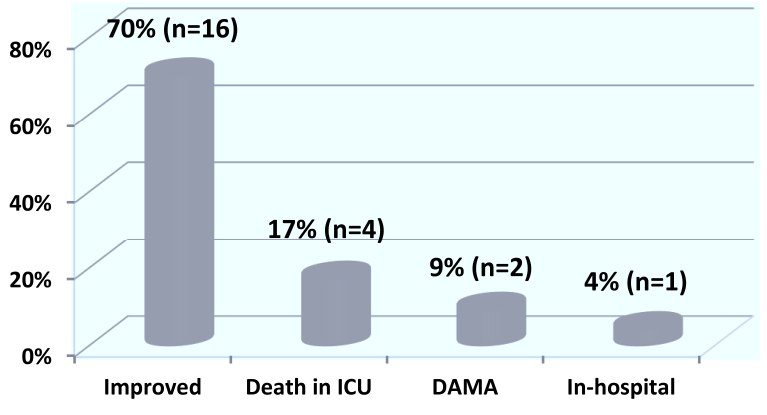

Figure 1. Outcome of the patients

Among 23 patients $2(9 \%)$ patients took discharge against medical advice (DAMA) due to financial constrain. One patient's treatment was ongoing in ICU till date.

Duration of fever of the patients before ICU Admission was $5 \pm 2.26$ day. Duration of ICU stay of 23 patients was $7 \pm 3$ days.

Patients who died in ICU, all of them $\{4(100 \%)\}$ had respiratory involvement, $3(75 \%)$ patients had cardiac involvement, $2(50 \%)$ patients had neurological involvement and $2(50 \%)$ patients had renal involvement. All of them were mechanically ventilated but 3(75\%) patients got inotrope support and $1(25 \%)$ patient got renal replacement therapy. Cause of death in 1 patient was septic and cardiogenic shock, 1 patient died due to cardiogenic shock only, 1 patient died due to septic shock with Acute kidney injury due to Rhabdomyolysis and 1 patient died due to meningoenchephalitis.

\section{Discussion}

Despite the involvement of many countries during the recent CHIKV outbreaks, there are few published studies on fatal cases. In this study majority of the affected patients were male. This finding is similar to another study where $(69 \%)$ were males and $(31 \%)$ were females. $^{21}$
Most of the affected patients were elderly patients having multiple comorbities in this study which is almost similar in other study. ${ }^{22}$ Another study differs from this, where maximum cases were in the age group of 21-35 years $(63 \%)$ having no comorbidities were reported.

Regarding clinical features, like this study other studies also showed that, apart from common presenting features like fever, arthralgia or arthritis, headache and myalgia, atypical menifestations like cardiac, neurological, renal, respiratory features can be present in Chikungunya patients and most of them required intensive care management. ${ }^{22-24}$ Though the guidelines say that diarrhea and vomiting are more common in children but this study revealed that a good number of adult patients had these symptoms as well which we can find in other study also. ${ }^{25,26}$

In this study lymphopenia was more frequent that is about $91 \%$ and thrombocytopenia was less and that is $43 \%$. This is similar with other study where lymphopenia was $87 \%$ and thrombocytopenia was $37 \%{ }^{25}$

Some studies showed hypocalcaemia in chikungunya patients ${ }^{25}$ but apart from hypocalcaemia, hyponatraemia is also found common in this study irrespective of diarrhea and vomiting.

Among the organ involvement respiratory involvement was more frequent (52\%) followed by renal involvement (47\%). Cardiovascular and neurological involvement were $34 \%$ each. This result is similar with another study $^{22}$ but differ from other studies where cardiovascular (54\%) followed by neurological (37\%) involvement ${ }^{20}$ or neurological involvement was more frequent. ${ }^{27}$

Mortality was $10 \%$ in one study where cardiac complications were common ${ }^{20}$ and another study showed mortality is $48 \%$ in patients admitted in intensive care unit. ${ }^{27}$ This study showed $17 \%$ mortality. Outcome 
with neurological involvement was good in another study ${ }^{15}$ which was similar with our study because in our study only 1 patient died due to neurological involvement. Sepsis, cardiac and renal involvements were common in expired patients. ${ }^{20,22,23}$

This was a single center study involving only one Intensive Care Unit. So no comparison with other Intensive Care Units of Bangladesh is possible through this study. Further larger multi-center study is warranted.

\section{Conclusion}

Though chikungunya virus infection is thought to be a benign disease it may be life threatening in elderly patients having comorbidities. It can lead to neurologic, renal, hepatic, respiratoy and myocardial complications and high mortality rate.

\section{Acknowledgement}

We express our gratitude to all the ICU staffs of BIRDEM hospital for their support.

Conflict of interest: Nothing to declare.

\section{References}

1. Schuffenecker I, Iteman I, Michault A, Murri S, Frangeul L, Vaney M-C, et al. Genome Microevolution of Chikungunya Viruses Causing the Indian Ocean Outbreak. PLoS Med 2006; 3(7): e263. https://doi.org/10.1371/journal. pmed. 0030263.

2. Deller JJ Jr, Russell PK. An analysis of fevers of unknown origin in American soldiers in Vietnam. Ann Intern Med 1967; 66: $1129-43$

3. McGill PE. Viral infections: alpha-viral arthropathy. BaillieresClinRheumatol1995; 9: 145-50.

4. Adebajo AO. Rheumatic manifestations of tropical diseases. Curr Opin Rheumatol 1996; 8: 85-89.

5. Ligon BL. Reemergence of an unusual disease: the Chikungunya epidemic. Semin Pediatr Infect Dis 2006; 17: 99-104.

6. Diallo M, Thonnon J, Traore-Lamizana M, Fontenille D. Vectors of Chikungunya virus in Senegal: current data and transmission cycles. Am J Trop Med Hyg 1999; 60: 281-86.

7. Vanlandingham DL, Hong C, Klingler K, Tsetsarkin K, McElroy KL, Powers AM et al. Differential infectivities of o'nyong-nyong and Chikungunya virus isolates in Anopheles Gambiae and Aedes aegypti mosquitoes. Am J Trop Med Hyg 2005; 72: 616-21.

8. Presti AL, Lai A, Cella E, Zehender G, Ciccozzi M. Chikungunya virus, epidemiology, clinics and phylogenesis: A review: Asian Pacific Journal of Tropical Medicine 2014; 925-932.

9. Chhabra M, Mittal V, Bhattacharya D, Rana UVS, Lal S. Chikungunya fever: A re-emerging viral infection. Indian $\mathbf{J}$ Med Microbiol 2008; 26: 5-12.

10. Chikungunya Fever Fact Sheet - CDC Division of Vector Borne Infectious Diseases.[Online]. Availiable from: http:// www.cdc.
11. Niedrig M, Zeller H, Schuffenecker I, Drosten C, Emmerich $\mathrm{P}$, Rumer L, et al. International diagnostic accuracy study for the serological detection of chikungunya virus infection. Clin Microbiol Infect 2009; 15: 880-84.

12. Pialoux G, Gauzere BA, Jaureguiberry S, Strobel M: Chikungunya, anepidemic arbovirus. Lancet Infect Dis 2007, 7: 319-27.

13. ICDDR B: First identified outbreak of chikungunya in Bangladesh, 2008.Health Sci Bull 2009, 7:1.

14. Maity P, Roy P, Basu A. A case of ADEM following Chikungunya fever. J Assoc Physicians India. 2014; 62: 441-2.

15. Chandak NH, Kashyap RS, Kabra D. Neurological complications of Chikungunya virus infection. Neurol India. 2009; 57: 177-80.

16. Gérardin P, Couderc T, Bintner M: Chikungunya virusassociated encephalitis: A cohort study on La Réunion Island, 2005-2009.Neurology.2016; 86: 94-102.

17. Mahendradas P, Avadhani K, Shetty R. Chikungunya and the eye: a review. J Ophthalmic Inflamm Infect. 2013; 3: 35.

18. Economopoulou A, Dominguez M, Helynck B. Atypical Chikungunya virus infections: clinical manifestations, mortality and risk factors for severe disease during the 20052006 outbreak on Réunion. Epidemiol Infect. 2009;137: 534-41.

19. Tandale BV, Sathe PS, Arankalle VA. Systemic involvements and fatalities during Chikungunya epidemic in India, 2006. J Clin Virol. 2009; 46: 145-9.

20. Alvarez MF, Bolívar-Mejía A, Rodriguez-Morales AJ, Ramirez-Vallejo E. Cardiovascular involvement and manifestations of systemic Chikungunya virus infection: A systematic review [version 2; referees: 2 approved, 1 approved with reservations] F1000Research 2017, 6:390 (doi: 10.12688/f1000research.11078.2)

21. Tomar MA, Hodiwala AVB, KhisteDD. Prevalence of Chikungunya Viral Infection in a Tertiary Care Hospital, Navi Mumbai Maharashtra. JMSCR 2017; 5: 15948-51.

22. Rolle A, Schepers K, Cassadou S, Curtier E, Madeux B, Storck $\mathrm{CH}$ et al.Severe Sepsis and Septic Shock associated with Chikungunya Viral Infection Guadeloupe, 2014. Emerg Infect Dis 2016; 22:891-94.

23. Sam I-C, Kamarulzaman A, Ong GSY, Veriah RS, Ponnampalavanar S, Chan YF et al. Chikungunya virusassociated death in Malaysia. Tropical Biomedicine 2010;27:343-47.

24. Rajapakse S, Rodrigo C, Rajapakse A. Atypical manifestations of chikungunya infection. Trans R Soc Trop Med Hyg. 2010; 104(2): 89-96.

25. Staikowsky F, Talarmin F, Grivard P, Souab A, Schuffenecker I, Roux KL et al. Prospective Study of Chikungunya Virus Acute Infection in the Island of La Re'union during the 20052006 Outbreak. PLoS ONE 2009 4(10): e7603.doi:10.1371/ journal. pone.0007603

26. Ray P, Ratagiri VH, Kabra SK, Lodha R, Sharma S, Sharma BS et al. Chikungunya Infection in India: Results of a Prospective Hospital Based Multi-Centric Study. PLoS ONE (a) 2012 7: e30025. doi:10.1371/journal.pone.0030025

27. Lemant J, Boisson V, Winer A, Thibault L, Andre H, Tixier $\mathrm{F}$ et al. Serious acute chikungunya virus infection requiring intensive care during the Reunion Island outbreak in 20052006.Crit Care Med. 2008;36:2536-41. 